\title{
DESAFIOS À FORMAÇÃO DE PROFESSORES ALFABETIZADORES EM CURSO DE PEDAGOGIA
}

Benedita de Almeida

\section{RESUMO:}

Este artigo discute resultados de pesquisa sobre a formação inicial de professores em um curso de pedagogia e seus desdobramentos na prática docente de ensino de língua materna nos anos iniciais do ensino fundamental. As reflexões, fundamentadas na teoria históricocultural do desenvolvimento, identificam e tomam como objeto de análise algumas características, contradições e impasses da prática pedagógica de um grupo de egressos do curso, professores nessa etapa escolar. Evidencia-se que as condições de formação e de trabalho do professor alfabetizador limitam a ancoragem de sua prática em bases científicas de conhecimento e a mobilização de saberes fundamentais veiculados no curso de graduação limitando-se as possibilidades de organização do ensino e de suas fontes de referência para contribuir à aprendizagem das crianças da classe trabalhadora. Identifica-se um descompasso entre as necessidades de formação nos anos iniciais de escolarização e as possibilidades dos professores que a efetuam, apontando a necessidade de redimensionamento na formação do professor e no curso de pedagogia.

Palavras-chave: Formação de professores - Linguagem e ensino - Alfabetização - Curso de pedagogia

\section{CHALLENGES TO THE LITERACY TEACHERS' EDUCATION IN THE PEDAGOGY COURSE}

\begin{abstract}
:
This paper discusses results on teachers' education research in a pedagogy course and its developments in children's mother language teaching during the first years of basic education. The ideas were based on historical-cultural theory of development and used as analysis subject some pedagogical practice characteristics and contradictions found in a group of teachers coming from the aforementioned course. It is shown that the conditions in which the teacher is built and in which he works limit his ability to anchor his practice in knowledge scientifically basis. That way, the possibilities of organizing teaching and its theoretical references with the goal of fulfilling the needs of the working class children are limited. One can, thus, identify a gap between the needs during the first years of basic education and the possibilities and acting horizon of the teachers who should enable it, showing consequently the necessity of a new approach to the teacher formation and also to the pedagogy course itself.
\end{abstract}

Keywords: Teachers' Education - Language Teaching - Literacy - Pedagogy Course

\section{Introdução}

A história do curso de pedagogia, no Brasil, desde 1939, é marcada por polêmicas quanto a sua identidade e à do pedagogo. As questões daí derivadas interferem na forma de organização do seu currículo e acompanham, até hoje, a definição de suas habilitações e do perfil do profissional por ele formado. Formando, inicialmente os "técnicos e especialistas em educação", tem ampliada, desde 1980, sua atuação na formação de professores para a 
educação infantil e anos iniciais do ensino fundamental (EF), mas é a partir dos anos 1990, principalmente pelas orientações da Lei de Diretrizes e Bases da Educação Nacional (LDB) 9394/96 (BRASIL, 1996), que passa a se constituir como o principal lócus de formação de professores para atuar nessas etapas de ensino, formação reconhecida como condição para melhora da educação básica brasileira (BERALDO; OLIVEIRA, 2010; BRASIL, 2006; BRZEZINSKI, 1996; PIMENTA, 2001).

Este artigo apresenta reflexões de pesquisa sobre a formação inicial de professores alfabetizadores em um curso de pedagogia e seus desdobramentos na prática docente de ensino de língua materna nos anos iniciais do EF. Para isso, procura identificar os saberes mobilizados na atuação pedagógica, por um grupo de egressos dos anos de 2002 a 2007, do curso de Pedagogia da Universidade Estadual do Oeste do Paraná (UNIOESTE), Campus de Francisco Beltrão, que atuavam, no ano de 2008, nos anos iniciais do EF, em escolas públicas do município. A partir da identificação de concepções, características, contradições e desafios da prática pedagógica de ensino de língua materna pelo grupo de egressos, bem como dos pressupostos teórico-metodológicos em que se ancora seu trabalho, procura-se analisar os saberes que o grupo mobiliza no exercício da docência e a relação com sua formação inicial. Ao estudar como esse campo de conhecimento se constitui na experiência de formação inicial e como se desdobra na constituição da atuação docente e do conhecimento do pedagogo para a concretude do processo de ensinoaprendizagem, analisam-se as contribuições e limites da proposta de formação inicial do curso de pedagogia para o ensino de língua materna nos anos iniciais do EF, questão que tangencia as importantes e complexas discussões sobre a identidade do curso de pedagogia e a do pedagogo.

A pesquisa base do estudo insere-se num amplo projeto coletivo, "Egressos de curso de Pedagogia: relações entre a formação inicial e o universo de atuação docente em escola de educação básica", no qual dez pesquisadores se envolvem, a partir de seus focos de pesquisa e atuação nos cursos de Pedagogia e Geografia da instituição. As informações e reflexões derivam de investigação qualitativa, de cunho sociocultural, inserida na linha de pesquisa "Formação de Professores, Saberes e Práticas Pedagógicas", do Grupo de Pesquisa RETLEE ${ }^{1}$. Um mapeamento dos profissionais atuantes nas escolas do município no ano de 2008 (ALMEIDA; FRANCISCHETT; PEDROSO, 2010) permitiu a identificação dos egressos sujeitos da pesquisa: 28 (vinte e oito) professores dos anos iniciais, que responderam a um questionário com dez questões fechadas e sete abertas, nas quais manifestaram suas percepções sobre a prática que desenvolvem, sobre os aprendizados obtidos no curso de Pedagogia e as possíveis relações que estabelecem entre essas duas instâncias formadoras. A presente reflexão pauta-se pelas questões do projeto relacionadas à formação e atuação de professores de língua materna nos anos iniciais do $\mathrm{EF}$, especificamente, às finalidades desse ensino e às necessidades de conteúdos de conhecimento e metodologias apontadas pelos egressos.

Emprega-se, de forma intencional, neste trabalho, a expressão "língua materna", para enfatizar um dado muito significativo ao ensino da alfabetização e da língua portuguesa em qualquer nível de escolaridade, o fato de que o objeto desse ensino faz parte do universo de referência e das práticas sociais do "sujeito que aprende". Desde quando inicia o EF - apenas para situar um momento - a criança conhece, domina e utiliza a linguagem verbal para suprir todas as necessidades interlocutivas (de expressão e compreensão), na modalidade de fala. Conhece as formas necessárias ao uso, como ordem das palavras, léxico, pronúncia, funcionamento geral da língua etc., tem uma gramática internalizada. O que não conhece ou não domina são as especificidades e funcionamento do sistema de escrita e a gramática normativa da língua. 
No início da escolarização, o ensino da língua materna tem o objetivo de introduzir a criança no domínio de uma outra modalidade de linguagem, um outro sistema de signos, com todas as relações e implicações próprias ao papel desses instrumentos semióticos na atividade humana - a língua escrita. Destaca-se, pois, o importante papel da instituição escolar para o ensino e a formação dos sujeitos, tomando a perspectiva histórico-cultural do desenvolvimento humano e o método dialético como fundamentos das reflexões. A linguagem, um dos focos centrais da discussão, é considerada na perspectiva discursiva ${ }^{2} \mathrm{e}$ em sua dimensão de signo que atua na relação humana com a realidade e na constituição cultural dos sujeitos.

O curso de pedagogia objeto da investigação foi implantado em 1994 e reconhecido em 1998, funcionando numa faculdade privada, incorporada a uma universidade estadual multicampi em 1999, a UNIOESTE, continuando a funcionar no campus de Francisco Beltrão, também criado naquele momento.

As finalidades do curso, previstas em seus projetos político-pedagógicos (PPP) foram, até o ano de 2003, "preparar o profissional para atuar na Educação Básica: Educação Infantil (Creches e Pré-Escola), Ensino Fundamental (quatro primeiras séries) e nas matérias pedagógicas do Ensino Médio" (UNIOESTE, 1999, p. 5); e, a partir de 2004³, formar "professores com vistas à atuação em Educação Infantil e Séries Iniciais do Ensino Fundamental; formação de professores para a atuação no âmbito da Gestão Escolar" (UNIOESTE, 2003, p. 3). A partir de 2008, suas finalidades ficaram assim dispostas: "formação de professores para o exercício da docência em Educação Infantil e Anos Iniciais do Ensino Fundamental; formação de professores para a atuação nos processos e procedimentos no âmbito da Gestão Escolar" (UNIOESTE, 2007, p. 3). A maioria dos sujeitos da pesquisa foi formada pelo primeiro PPP, somente um pelo segundo, e nenhum pelo terceiro.

A formação de professores para os anos iniciais do EF, portanto, é uma finalidade expressa nos projetos político-pedagógicos orientadores do curso, cuja estrutura didáticocurricular converge com essa finalidade. E a formação para atuar nessa fase implica a dimensão das áreas e disciplinas específicas de conhecimento para ensino nessa etapa escolar, pois toda atividade de ensino tem um objeto, não opera num vazio, refere-se a um conhecimento que é função da escola selecionar e transmitir às novas gerações de estudantes.

$\mathrm{O}$ ingresso no EF inaugura um período diferenciado de aprendizagens na experiência infantil, pela ampliação do convívio da criança com processos sistemáticos e intencionais de ensino-aprendizagem, que introduzem noções e fundamentos das áreas de conhecimento, imprescindíveis a sua formação. A importância desses processos, no entanto, ultrapassa esse patamar, pois, como afirma Vigotski (1998, p. 118), “o aprendizado adequadamente organizado resulta em desenvolvimento mental e põe em movimento vários processos de desenvolvimento que, de outra forma, seriam impossíveis de acontecer". Se essa etapa escolar é fundamental para a formação do indivíduo, de modo correlato, também o é a formação do professor que conduz esse processo, o que justifica a análise dessa formação, proposta neste estudo.

$\mathrm{O}$ artigo constitui-se em quatro seções, além dessa introdução. A primeira destinase a uma reflexão sobre trajetórias e objeto do ensino de língua materna na escola, enfatizando a transição do foco da gramática normativa para a questão identitária relacionada à linguagem e as decorrentes implicações possíveis dessa mudança nas práticas escolares. Na segunda, a partir de informações da pesquisa, apresentam-se concepções dos egressos do curso de pedagogia sobre o ensino de língua materna que realizam nos anos iniciais do EF e seu significado. Os conteúdos das respostas dos sujeitos são divididos em 
cinco categorias que constituem itens da seção, cujo conteúdo oferece subsídios à formação do professor, discutindo-se o importante estatuto da gramática na práxis linguística e no desenvolvimento humano. Na terceira seção, analisam-se características, desafios e impasses no ensino de língua materna, a partir das referências dos sujeitos sobre conteúdos e metodologias, destacando-se a objetivação do seu trabalho, com fundamentos na teoria da atividade, de Leontiev (1988). Por último, apresentam-se problematizações gerais sobre o processo, apontando a complexidade da constituição desse professor no curso de pedagogia, cuja ampla abrangência pode representar limites à formação profissional.

\section{Pontos de partida: trajetórias do ensino de língua materna na escola}

Nas últimas décadas do século XX, com a ampliação e avanço da pesquisa linguística e com a introdução dos estudos de Bakhtin (2000, 2002) e Vigotski (1998, 2009) sobre as relações entre a linguagem e o desenvolvimento humano, o campo de ensino de língua materna recebe um direcionamento qualitativamente diferenciado para tratar de temas como alfabetização, ensino de leitura e escrita, ensino de gramática, de língua portuguesa, enfim.

Como aspecto relevante desses aportes, evidencia-se a crítica ao "caráter excessivamente normativo do trabalho com a linguagem nas escolas brasileiras" (FARACO; CASTRO, 2008, p. 2), que toma como principal preocupação e como base do ensino da língua materna o ensino de regras, normas e nomenclatura gramaticais. Assim realizado, esse ensino desconsidera a realidade da língua - a sua realização na singularidade da interlocução, as condições das situações interlocutivas, que significam a materialidade da língua escrita na sua efetivação como prática social. O ensino da alfabetização tem acompanhado essa tendência, que torna a aquisição da escrita o aprendizado de uma linguagem artificial, desmontada em unidades sem sentido e completamente distante de propósitos dos usuários. Tomando o ensino de regras e conceitos da gramática normativa como objeto central do ensino - quase sempre desde os primeiros anos de escolarização - confunde-se ensino de língua com ensino de gramática, e outros aspectos importantes e necessários, como a leitura e a escrita ${ }^{4}$, ficam em segundo plano.

Por outro lado, os estudos que consideram o papel da linguagem no desenvolvimento buscam contrapor, a um modelo de ensino a-histórico, o reconhecimento de que os fatos linguísticos se relacionam a sujeitos sociais e a sua cultura. Nessa perspectiva, "a verdadeira substância da língua não é constituída por um sistema abstrato de formas linguísticas nem pela enunciação monológica isolada, nem pelo ato psicofisiológico de sua produção, mas pelo fenômeno social da interação verbal", que constitui "a realidade fundamental da língua" (BAKHTIN, 2002, p. 123).

Essa premissa buscará aproximar o ensino de qualquer modalidade de linguagem, incluindo o período de alfabetização, ao seu real estatuto de prática cultural. Ou seja, há que se reconhecer, nesse ensino, a importância das atividades interpessoais que, mediadas pela linguagem, impregnam os signos de significado e sentido ${ }^{5}$ que serão internalizados e passarão a formar a consciência individual - constituída sócio-historicamente e desenvolvida na apropriação da cultura (VIGOTSKY, 2009).

Desse pressuposto, num processo que investiga a formação e prática de professores de língua materna nos anos iniciais do EF, algumas questões são relevantes: qual é o objeto do ensino de língua materna, o ensino de unidades linguísticas abstratas, regras e nomenclaturas gramaticais, ou o uso proficiente da linguagem verbal, em suas diversas 
modalidades, nas diferentes situações e nas relações com o conhecimento? Essa definição é crucial para a organização do ensino. Em se tratando da língua escrita, o objeto se refere ao domínio da leitura e escrita como atividades humanas de interlocução e constituição de significados - a manifestação viva da linguagem. Integrados nessa definição estão, também, os fatores de desenvolvimento intelectual que o aprendizado da modalidade escrita da língua promove, pelas atividades de análise, deliberação e abstração que sua prática exige (VIGOTSKI, 1998).

Com o advento de pressupostos da linguística no ensino de língua materna, o texto passou a ser seu objeto, e a gramática a ser estudada "na perspectiva de sua funcionalidade textual", o que implicaria o abandono da memorização de regras de forma descontextualizada e abstraída do uso efetivo. Mais do que alteração de materiais e metodologias, essa mudança representa uma importante visada epistemológica, pois implica um outro entendimento sobre a linguagem e as relações que com ela mantêm os indivíduos. Nessa perspectiva, "o aprendizado com a linguagem se dá por meio do uso que se faz dela na interação (oral ou escrita) que se estabelece com o outro, seja ele real ou virtual" (FARACO; CASTRO, p. 2). Essas interações incluem as complexas mediações de leitura e escrita que põem os sujeitos em relação com o conhecimento e a cultura humana.

Além do conceito de interação verbal (BAKHTIN, 2002; VIGOTSKY, 2009), as bases dessa proposta encontram ressonâncias, também, no conceito de gêneros do discurso (BAKHTIN, 2000), que evidencia o elo da linguagem com a esfera da atividade humana, por se referir aos atos mediados pela interlocução, por conseguinte, à variedade das práticas linguísticas de um sujeito e seu grupo social. Em cada esfera de atividade humana e de estrato social, criam-se formas específicas de linguagem - os gêneros -, cujas unidades são os enunciados, e não as orações ou palavras soltas. Numa sociedade de classes, ao se relacionarem com o universo social do sujeito que aprende a escrita, suas práticas linguísticas revelam seus conhecimentos e os do seu grupo cultural. Exatamente por isso, constituem-se impregnadas pelo poder atribuído à escrita nessa sociedade.

Considerar tais pressupostos implica pensar uma proposta pedagógica de ensino da língua escrita voltada para a atividade humana e sua realização na sociedade, tendo a escola como instituição responsável por socializar o conhecimento linguístico e permitir sua apropriação e ampliação pelos sujeitos. Implica, também, considerar o estreito vínculo da linguagem com a subjetividade, seja no âmbito do desenvolvimento pessoal e de conhecimento proporcionado pelas mediações dos sentidos via interações sociais, pelos fatores propulsores de atuação mais consciente que o aprendizado e uso da escrita forçam na criança (VIGOTSKY, 2009); seja no âmbito das relações ideológicas que atravessam os contextos de existência de professores e alunos.

Propostas pedagógicas ancoradas nessas posições (muito mais almejadas do que praticadas), no entanto, introduziram uma desorientação no trabalho de ensino da língua, retirando-lhe o seu objeto de até então - a tradicional gramática normativa -, mas sem que os professores tivessem clareza sobre o que pôr no seu lugar. A mudança reduziu-se a alterar materiais e atividades pedagógicas, sem atinar com a importante questão conceitual envolvida. O que ficou no lugar foi a vaga expressão "trabalho com o texto" que, na maioria das vezes, reduziu-se a recortar dele frases, expressões ou palavras para retirar, sublinhar, circular, classificar elementos gramaticais ou transformar, flexionar segmentos linguísticos. Ou seja, continua-se a trabalhar com a gramática normativa, mas de forma velada e superficial, logo, também sem compreensão, e, talvez, com resultados mais nefastos do que benéficos aos estudantes. É importante lembrar que a introdução desses aportes teóricos no ensino da linguagem coincide com um período de ampliação do acesso escolar no Brasil, a partir da formação e expansão da "escola de massas", nos governos 
militares, pela qual novos alunos foram integrados à escola pública brasileira. Num movimento correlato, segundo Marinho (2000), passa-se a haver menores exigências no "recrutamento" de professores, o que tem gerado desqualificação da formação inicial e um maior investimento em materiais didáticos para suprir as lacunas consequentes.

Sem resolver a questão epistemológica inerente à mudança de compreensão sobre a linguagem, as propostas que tentam se ancorar na perspectiva da interação (incluindo a questão do letramento, que será discutida mais adiante) não promovem alteração significativa no ensino nem benefício para quem aprende, e, muitas vezes, o trabalho educativo cai no improviso ou na indeterminação. Definir o que se ensina, quando se ensina língua na escola, é tarefa básica da dinâmica do trabalho pedagógico, assim como é pressuposta a necessidade de um domínio de conhecimento, pelo professor. Conhecimento que, para além das dimensões mais diretamente relacionadas aos conteúdos e à atuação pedagógica, remeta à compreensão das relações políticas e sociais de inserção do professor nos âmbitos de trabalho, exercício profissional e contexto social de seu tempo, pois, pelo caráter ideológico ${ }^{6}$ intrínseco à linguagem, junto com as práticas desenvolvidas no ensino da língua, os sentidos para ela concebidos e os conteúdos que veiculam também são ensinados (GERALDI, 1997).

A investigação sobre a formação em curso de pedagogia e o trabalho pedagógico de ensino de língua materna nos anos iniciais pelo grupo de egressos vem demonstrando a complexidade dessa relação. Certamente que não se a concebe unidimensional, dadas as importantes e diversas mediações culturais que também interferem na formação do pedagogo alfabetizador, como sujeito histórico, e no ensino, atividade também atravessada por múltiplas determinações. Contudo, na relevância que aqui se atribui à educação escolar, há que se reconhecer que a formação inicial em curso de pedagogia pode ser fator decisivo para a constituição da identidade e o desenvolvimento profissional do professor. No caso dos sujeitos desta pesquisa, professores dos anos iniciais do EF, essa formação constituiria o ponto de partida para a composição da docência nas suas dimensões profissional, política e epistemológica (WEBER, 2003). Representaria, portanto, diferencial significativo para a possibilidade de aquisição e sedimentação de uma "base de conhecimentos", a ser articulada no e com o exercício da profissão. Pimenta (1996) também destaca a importância da formação inicial para a constituição do conhecimento científico, técnico e o da(s) disciplina(s) que os professores lecionarão.

Com esses fundamentos, a análise organizada no processo investigativo consubstancia as reflexões que se apresentam a seguir sobre a complexa dinâmica de relações e de formação que integra e caracteriza o conhecimento profissional e o trabalho educativo no ensino de língua materna, do grupo de egressos.

\section{Percepções dos professores sobre o ensino de língua materna nos anos iniciais do EF}

As informações para a pesquisa, como expresso, foram reunidas a partir de respostas dos sujeitos a um questionário. No esforço de compreender como, na experiência docente, os sujeitos dialogam com os conhecimentos fundamentais para seu trabalho no ensino de língua materna, analisam-se, neste tópico, suas respostas ao questionamento "acha importante ensinar língua portuguesa (LP) ${ }^{8}$ ? Por quê?"

Os vinte e oito egressos responderam afirmativamente, e quatro deles não justificaram a razão por que atribuem importância à disciplina. Na perspectiva discursiva com que se considera a linguagem neste trabalho, e na situação de pesquisa em que se encontram os sujeitos, o "não dito" embebe-se de sentido, tanto quanto o manifesto. Podese afirmar que as não justificativas representam casos de falta de clareza ou de definição 
quanto ao papel do ensino de LP na formação das crianças dos anos iniciais do EF. Ou seja, representariam a ausência de sentido para esse ensino.

Trata-se de fato relevante no contexto de docência nessa etapa escolar, em que a criança está em fase de aprendizagem da língua escrita, um sistema simbólico que permeia as relações sociais e atua no seu desenvolvimento, tanto na restrita dimensão individual, como função do pensamento, como na dimensão sociocultural, como fator de aquisição dos códigos da cultura (VIGOTSKY, 2009).

As justificativas apresentadas pela maioria dos egressos (vinte e quatro) oferecem diversos elementos para análise de suas representações e percepções sobre a linguagem e o ensino de língua materna que realizam. Todas as razões manifestas foram contadas ${ }^{9}$ e, em síntese, expressam: a) concepções de linguagem (nove ocorrências); b) naturalização do ensino de língua materna no processo de escolarização (nove ocorrências); c) ensino da língua como mecanismo de participação social (cinco ocorrências); d) caráter pragmático ou utilitário da língua (quatro ocorrências); e e) caráter constitutivo da linguagem (três ocorrências).

Os sentidos e conteúdos que os sujeitos atribuem ao ensino, expressos nessas categorias, são produtos de uma cultura que se movimenta no universo da escola e da formação - que eles têm e que fazem -; cultura que, por sua vez, é um conjunto de categorias em que os sujeitos se movimentam para dar sentido ao ensino, de forma responsiva, nessa grande corrente interlocutiva, que é sua formação. O saber que expressam constitui sua experiência e é o elemento que transmitem no ato de ensino. É válido, portanto, tentar compreender o que significam nesse universo, tarefa proposta na sequência de análise.

(a) Concepções de linguagem: as concepções de linguagem (presentes em justificativas de nove sujeitos para a importância do ensino) têm implicações no processo de ensino e aprendizagem da língua materna, cuja materialidade envolve dimensões do conhecimento do professor sobre o objeto a ensinar, no caso, um objeto intrinsecamente relacionado à constituição das identidades - a linguagem.

De um modo geral, no âmbito de orientação das práticas escolares, destacam-se três concepções de linguagem, que representam modos de concebê-la em diferentes momentos do estado do conhecimento sobre esse objeto, o que lhes daria uma dimensão diferenciadora em termos progressivos. No entanto, todas elas estão presentes nas respostas dos professores, convivendo, isoladamente, no mesmo momento histórico: linguagem como expressão do pensamento, linguagem como comunicação e expressão e linguagem como interação social.

A concepção de linguagem como expressão do pensamento vigorou na gramática tradicional (normativa), significando apenas um veículo de expressão do pensamento, sem levar em conta as trocas interlocutivas, e a língua a ser ensinada/aprendida refere-se apenas à norma padrão - um conjunto de regras a serem seguidas, para aprender a escrever e falar corretamente. São excluídos os usos efetivos da língua e os objetivos de desenvolver a competência comunicativa, o conhecimento da forma e da função da língua, o reconhecimento das variantes, o pensamento e o raciocínio (TRAVAGLIA, 1996, p. 17).

São exemplos dessa concepção alguns depoimentos dos sujeitos da pesquisa: Para ele decodificar, se expressar com clareza. [...]; Expressar-se por meio da(s) linguagem(ns).

A concepção de língua como instrumento de comunicação, originada do estruturalismo, toma a língua como um código, por cuja combinatória é possível transmitir mensagens. Nessa perspectiva, a gramática é concebida como um conjunto de regras que são seguidas, e "a preocupação central [do ensino] é tornar conhecidas, de forma explícita, 
as regras de fato utilizadas pelos falantes" (POSSENTI, 1996, p. 65), a gramática descritiva. Mesmo que haja erros, eles seguem um padrão, portanto não se critica o falante ou a forma usada, apenas se a descreve e classifica como diferenças linguísticas. Nessa concepção, a língua continua pensada de forma abstrata, homogênea e desarticulada dos usos concretos. O foco está no código, que deve ser utilizado sempre de determinada forma para se estabelecer a comunicação. Quando define a língua como meio de comunicação, o estruturalismo exclui o papel do falante no sistema linguístico, o que implica a não existência de interlocutores, mas de emissores e receptores, codificadores e decodificadores (POSSENTI, 1996). Algumas justificativas dos sujeitos exemplificam essa perspectiva: Comunicação é essencial. / Comunicar-se com o outro. / Fundamental para comunicação. / É a comunicação de sentimentos, idéias, conceitos.

Embora com uma única ocorrência nas respostas - Ninguém nasce sabendo, tudo se aprende na interação - é significativa a manifestação da concepção de linguagem como interação, que também a relaciona ao aprendizado. Nessa perspectiva, a língua é atividade humana e social e se realiza no contexto histórico-cultural dos indivíduos. Como consequência, o objetivo de seu ensino é desenvolver as capacidades para o emprego adequado nas diversas situações de interlocução, considerando os conteúdos que veicula, visto que a linguagem se trata de uma arena com valores em disputa (BAKHTIN, 2002; VIGOTSKY, 2009).

$\mathrm{Na}$ proposta de ensino fundamentada na concepção de linguagem como interação não se trata, contudo, do abandono da gramática. Nessa proposta, considera-se, em primeiro lugar, a gramática como práxis linguística, e não simplesmente como norma ou descrição da língua. E quando se trata de ensinar gramática, há que se considerarem os efeitos de desenvolvimento que sua aprendizagem produz, por fazer com que a criança se torne consciente das relações funcionais de aspectos linguísticos com que atuava inconscientemente. Como afirma Vigotsky (2009), o aprendizado da gramática e da escrita contribui para que a fala da criança passe para um nível mais elevado de desenvolvimento. $\mathrm{Na}$ atividade linguística humana, esse elemento também é diferenciador dos gêneros do discurso e contribuinte de sua transição de primários a secundários, com toda a implicação cultural e política que impregna tal transição.

No seu estatuto de explicitar categorias do funcionamento da realidade da língua na prática dos sujeitos, a gramática constitui as relações linguísticas e atualiza a linguagem na prática social, atuando como signo, portanto mediando as relações entre homem e realidade.

Ou seja, na prática pedagógica com língua materna não se trata de "ensinar um pouquinho de gramática", como alertam Faraco e Castro (2008), mas de repensar o seu papel na interlocução e na formação do sujeito, para, a partir daí, orientar o ensino. A gramática é aprendida por todo falante no ato interlocutivo de aprendizagem da língua (ao aprender a falar, a ler, a escrever). As práticas de ensino de oralidade, leitura e escrita devem ser consideradas na relação com os objetivos de desenvolver as capacidades do falante para seus propósitos interlocutivos, adequação aos contextos e possibilidades de posicionamento pessoal; ler com compreensão, refletir sobre o texto lido e poder exercer sua capacidade crítica e estética; e desenvolver o uso da língua escrita nas diversas práticas sociais, considerando interlocutores, objetivos, assunto, propósitos, gêneros, suportes e contexto de produção. Isso significa que fala, leitura e escrita são parte de um projeto pessoal para atender às necessidades de sujeitos historicamente situados: informação, formação, diversão, prazer estético, emoção, entre outros. A construção de sentidos na interação é a base desse projeto, e as questões gramaticais são recursos valiosos para a constituição do texto que, entendido como materialização do discurso, deve ser a unidade 
básica do trabalho com a língua.

(b) Naturalização do ensino de língua materna no processo de escolarização: há nove manifestações dos sujeitos da pesquisa que caracterizam a importância do ensino de LP por elementos próprios do processo de escolarização. Ou seja, justificam a disciplina por si mesma, como instrumento para a escolarização, como exemplificam alguns depoimentos: Porque tudo começa na alfabetização. Porque tudo começa com a LP. Faz parte de um todo principalmente da sua alfabetização. Pois sem ela as outras matérias ficam sem voz. É o nosso ponto de partida. Para a criança poder apreender-se da Língua Portuguesa. Ampliar e conhecer os diferentes tipos de dialetos, regras gramaticais, etc. Porque é necessário aprender a ler, escrever e compreender os conteúdos de português que são de muita importância na nossa vida. Porque é a nossa língua mãe.

Esse aspecto pode ser relevante no quadro da escola pública brasileira, eivado de problemas para constituir "proficiências" em leitura e escrita - de fato, uma condição básica para a própria educação escolar. Na história da alfabetização, essa tendência é evidenciada nos estudos de Cook-Gumperz (1991), que relatam como, a partir do século dezoito até o final do século dezenove, a escola tornou-se o lócus natural da leitura e escrita, e a alfabetização o passo essencial da escolarização. Conforme a autora, à época, ao retirar das comunidades, igrejas e outras instituições esse ensino, havia a intenção de controle e regulação das classes que seriam ou poderiam ser alfabetizadas (escolarizadas).

Na pesquisa, a constância e frequência de uso da língua justificariam e legitimariam seu ensino na escola, como fatores de naturalização. Essa centralidade da língua na experiência escolar não deixa de representar uma forma de classificação dos saberes. Implica, também, uma visão de que seu aprendizado asseguraria uma posição superior na sociedade, ao mesmo tempo em que se materializa como uma forma de atuar na tessitura social, pressupondo "uma socialização universal, [...], válida para qualquer sujeito, desligada das classes sociais e do caráter histórico" (VARELA, 1995, p. 48).

É certo que, no início da escolarização do EF, a alfabetização constitui uma ênfase, entre outras, por ser um instrumento à própria escolarização da criança. Não se trata de nenhuma pretensão a hierarquizar disciplinas ou áreas de conhecimento, mas, simplesmente de reconhecer que o aprendizado da língua escrita dota a criança de um importante instrumental para dar conta de suas atividades no início e prosseguimento da vida escolar. Vencida a fase de alfabetização inicial, a língua escrita continua sendo um instrumento da escolarização, e os problemas advindos do seu aprendizado passam a representar importantes contornos no desempenho geral do estudante.

Isso não ocorre somente como consequência da suposta onipresença da língua na atividade escolar, mas pela possibilidade de criação inerente ao aprendizado e uso da escrita. Assumir essa possibilidade é tomar a escrita na sua plenitude de prática social e humana, que põe em contato diferentes subjetividades, por seus textos e enunciados, numa cadeia contínua, em que a mediação da palavra permite conectar-se ao objeto de pensamento com vistas a sua compreensão (BAKHTIN, 2000, 2002). É também considerar suas características de elemento organizador do pensamento e da experiência humana, para objetivar o conhecimento dessa experiência - ao mesmo tempo, prática cultural, prática de apropriação e constituição de cultura (VIGOTSKI, 1998). Tal concepção de escrita, aqui assumida, considera-a uma complexa atividade de pensamento. Enquanto exige, de quem escreve, a análise deliberada e consciente da situação, para representá-la na materialidade do texto, possibilita o controle consciente do fluxo de pensamento, atua no desenvolvimento intelectual do sujeito, convoca-o a se posicionar e o integra na corrente cultural e ideológica do grupo de usuários e praticantes da escrita.

c) Ensino da língua como mecanismo de participação social: na sociedade atual, 
em que a cultura escrita orienta e organiza as mais diversas atividades humanas, é significativo ter o trabalho de ensino da LP justificado pelas suas possibilidades de constituir mecanismo de inclusão e participação social, justificativa com cinco menções pelos sujeitos, assim exemplificadas: [...] podendo fazer parte do mundo letrado. Para saber em primeiro lugar se defender. Porque acredito que a linguagem também é um instrumento de inserção social. É o caminho para o mundo letrado. O mundo exige muito hoje dos homens, temos que estar letrados para o mundo.

Os argumentos apontam para o conceito de letramento, tomado como instrumento de inserção crítica do indivíduo na sociedade. Apesar da polêmica que o termo suscita no mundo acadêmico, há que se reconhecer que ele integra os discursos orientadores de políticas educacionais e circula no universo dos professores, cabendo, pois, trazer à luz suas implicações.

Nas últimas décadas, sua introdução na esfera do ensino de língua materna pretende articular os aspectos sócio-históricos da aprendizagem da língua escrita ao seu ensino e conceder-lhe um estatuto de prática social. Etimologicamente, o termo é adaptação do inglês "literacy" e significa a condição que adquire o sujeito ao aprender e usar a escrita. $\mathrm{Na}$ dimensão individual refere-se ao desenvolvimento de habilidades para ler e escrever; na social, corresponde aos usos da escrita nas diferentes práticas sociais. Em ambas, é envolvido por aspectos políticos e ideológicos que se referem, por exemplo, a quem define as habilidades a serem ensinadas, para quem, em que contexto as práticas de leitura e escrita são desenvolvidas e com que propósitos, que conteúdos veiculam, entre outras (KLEIMAN, 1995; SOARES, 2006).

A partir de Soares (2006, p. 17), "implícita nesse conceito está a idéia de que a escrita traz consequiências sociais, culturais, políticas, econômicas, cognitivas, linguísticas, quer para o grupo social em que seja introduzida, quer para o indivíduo que aprenda a usála".

No ensino-aprendizagem, trata-se de possibilitar aprender e usar a escrita, num processo que refuta as práticas mecânicas de ensino meramente instrumental da alfabetização, para situá-la na sua dimensão interlocutiva. Nesse movimento, o significado das aprendizagens para o estudante e as formas como a escola lida com as diferenças linguísticas e culturais inserem-se no ensino. Trata-se, também, de considerar as condições de uso da escrita pelos diferentes grupos e de se contrapor à pressuposição de efeitos universais do letramento, pois que são "correlacionados às práticas sociais e culturais dos diversos grupos que usam a escrita" (KLEIMAN, 1995, p. 16). Isso significa que a escrita é um bem cultural, e fazer parte do mundo letrado é uma conquista que a escola tem a obrigação de possibilitar a todos os estudantes. No caso dessa pesquisa que trata da formação e atuação de professores alfabetizadores, não se pode esquecer que os anos iniciais do EF configuram uma situação potencial para acesso e apropriação de bens culturais, que estará, contudo, atrelada ao conhecimento, nível de letramento e condições de trabalho do professor.

d) Caráter pragmático ou utilitário da língua: a LP, como "necessidade da vida diária", isto é, em seu caráter utilitário e pragmático, justifica seu ensino na escola, em quatro manifestações dos sujeitos: Necessária e importante no dia a dia do ser humano. Faz parte da vida diária e é base para a vida (mundo, trabalho, crescimento). É necessário na vida diária. Necessidade diária.

Essa argumentação precisa ser analisada com cuidado, por conter duas dimensões que podem ser visceralmente antagônicas.

Pela primeira, resgata-se, no ensino escolar, o elo da língua com a experiência cultural humana, ou, pelas palavras de Bakhtin (2000), com "a esfera da atividade humana" 
- pelos gêneros do discurso, que representam toda forma de concretização da linguagem. Por essa via, a língua constitui instância de realização da experiência humana de e com a linguagem, o que envolve pensar o seu ensino voltado ao desenvolvimento das capacidades de interlocução pela escrita em todos os âmbitos de possibilidades, atuando, portanto no desenvolvimento do sujeito e na sua possibilidade de intervir na realidade social.

Uma segunda dimensão possível de estar presente nessa argumentação é restringir o ensino de língua materna aos usos da escrita apenas como um simples instrumento técnico de satisfazer necessidades da sobrevivência do sujeito na dimensão pragmática da prática social. O risco dessa tendência são os possíveis mecanismos de poder, controle e alienação que permeiam a distribuição do uso da escrita na sociedade contemporânea. Assim, decorreria o risco de subvalorizar os aspectos intelectuais envolvidos na aprendizagem da escrita, expansíveis à relação do sujeito com o conhecimento sistematizado e sua ampliação.

Neste texto, já se expuseram fatores relevantes sobre a dimensão cultural da escrita, portanto, ao se caracterizá-la como prática social e ressaltar seus usos sociais não se pretende reduzi-la a instrumento de atendimento a demandas de um sistema produtivo que requer determinadas capacitações do indivíduo ou cerceia sua constituição cultural.

e) Caráter constitutivo da linguagem: por três vezes, a linguagem como fator constitutivo da identidade individual e cultural ocorre nos depoimentos como justificativa para o ensino da LP: Porque desenvolve a construção da sua história, a cultura. Porque assim ela será construtora do sistema social e não só expectadora. Ninguém nasce sabendo, tudo se aprende na interação.

Embora sejam as justificativas menos frequentes, cabe ressaltar o valor de sua ocorrência, pois se relacionam às mais significativas dimensões da linguagem. Desse ponto de vista, trata-se, efetivamente, de distanciar seu ensino de elementos abstratos e inseri-lo no campo objetivo da formação do sujeito, considerando os aspectos de desenvolvimento intelectual da criança potencializados pelo aprendizado da escrita, pelo papel dos signos na formação das funções psicológicas superiores. Segundo Vigotski (1998), na fase da escolarização inicial, essas funções estão em desenvolvimento e recebem interferências do aprendizado em geral, mas a escrita atua de um modo particular, por ser do domínio semiótico e caracterizar-se por mobilizar a atividade consciente, o controle deliberado, a análise e um alto nível de abstração; e por exigir um esforço para busca e expressão de um conjunto determinado de "ideias" ou conhecimentos que precisam ser selecionados para compor a materialidade do texto, mediante o encadeamento de palavras que traduzam a intenção de escrita e, ainda, considerando o possível leitor ausente e o efeito que se deseja causar.

Ainda nessa perspectiva, cabe destacar que a linguagem, como elemento que guarda e veicula os códigos da cultura, também constitui o material da consciência, ou seja, os próprios códigos. Como muito bem salienta Bakhtin (2002, p. 108), "os indivíduos não recebem a língua pronta para ser usada; eles penetram na corrente da comunicação verbal; ou melhor, somente quando mergulham nessa corrente é que sua consciência desperta e começa a operar". O caráter constitutivo da escrita ainda pode ser ressaltado pelo fato de que, em todos os usos da linguagem permanecem presentes os marcos sociais e ideológicos que a caracterizam como uma atividade que mantém o sujeito em relação dinâmica com seus enunciados, inscritos na ordem social da vida.

A presença desse princípio de constituição pessoal nas respostas dos sujeitos, portanto, é muito importante, pois ele é fundamental para a organização do ensino, desde o início da alfabetização. Refere-se a reconhecer que a aprendizagem da escrita e leitura não se reduz à questão físico-motora, nem à utilitarista-pragmática. Muito mais que isso, 
refere-se à constituição de conhecimentos pelo sujeito, por isso, com intensa atuação na sua identidade, pois "na realidade, não são palavras o que pronunciamos ou escutamos [ou escrevemos e lemos, pode-se acrescentar], mas verdades ou mentiras, coisas boas ou más, importantes ou triviais, agradáveis ou desagradáveis, etc." (BAKHTIN, 2002, p. 95), e que impregnam a palavra de um conteúdo ideológico e vivencial intenso.

\section{Elementos para objetivação do ensino de língua materna pelos egressos}

A pesquisa buscou identificar as "maiores necessidades de conteúdos de conhecimento e de metodologia" do grupo de egressos, para, a partir dessa objetivação, refletir sobre os desdobramentos da sua formação, em curso de pedagogia, no trabalho pedagógico. As respostas dos sujeitos contêm elementos relevantes para reflexão sobre suas relações com o trabalho que realizam e os conhecimentos de que poderiam ter se apropriado no processo de formação: em primeiro lugar, seis sujeitos não responderam à questão, e seis não apresentaram uma resposta apropriada ao solicitado na pergunta.

Para analisar esse elemento, considera-se que o trabalho humano pode ocorrer de forma consciente ou alienada, conforme as relações do sujeito com o objeto desse trabalho e as possibilidades de transformação da realidade que tais relações possibilitam (LESSA, 1995). A objetivação do trabalho do professor refere-se ao ensino, um trabalho intelectual, relacionado à cultura e às diversas áreas de conhecimento, e cujo resultado ocorre, ou não, pela mediação pedagógica que efetua. A atividade do professor tem a finalidade de transformar o status quo dos saberes e conhecimentos dos alunos e resultar em aprendizagens. Na perspectiva histórico-cultural, Leontiev (1988) denomina de atividade os processos psicológicos que se realizam em função de uma finalidade que mobiliza o sujeito à realização da ação. Para o autor, são os objetos das atividades que as distinguem entre si, "uma vez que é exatamente o objeto de uma atividade que lhe dá a direção determinada, ou seja, o objeto de uma atividade é seu verdadeiro motivo" (LEONTIEV, 1988, p. 62).

A identificação, pelos sujeitos da pesquisa, das necessidades de conteúdos de conhecimento e de metodologia para ensinar língua materna e as justificativas sobre a importância atribuída a esse ensino relacionam-se direta e intrinsecamente ao objeto desse ensino nos anos iniciais do EF, que, considerada a interação verbal como a substância da língua (BAKHTIN, 2002), pode assim ser definido:

[...] a leitura e a escrita, bem como os usos da língua em situações de instâncias públicas, que, em última análise, se orientam pela cultura escrita. Complementarmente, [...] estaria a reflexão sobre a língua, seu funcionamento e valores, os instrumentos de análise e reflexão linguística e a estética literária (BRITTO, 2003, p. 50, grifo nosso).

Tomando a escola como instituição intencionalmente organizada para promover a aprendizagem das novas gerações, no ensino da língua materna, evidencia-se o papel decisivo do professor na formação dos estudantes, para torná-los usuários da língua escrita na perspectiva de sua inserção num âmbito da cultura que implica relações complexas de aquisição e ampliação de conhecimentos. Trata-se, pois, de considerar, nesse trabalho de ensino, os elementos constituidores da escrita que a articulam à emancipação e desenvolvimento humanos.

O professor de língua materna é um importante agente do letramento das crianças, e seu trabalho envolve, para além de trazer a língua viva das práticas sociais ao processo de ensino e aprendizagem, um amplo conhecimento das dimensões conceituais e ideológicas que isso significa para o trabalho educativo planejado. A forma como ele organiza seu 
ensino, os desafios que encontra e as estratégias que produz para superá-los oferecem um importante suporte para análise do seu conhecimento. As escolhas feitas em sala de aula (de conteúdos, metodologias, materiais, atividades) precisam ser providas de discernimento e clareza teórica, por isso, relacionam-se ao preparo profissional para exercer seu trabalho. O desconhecimento ou falta de clareza sobre o que e como ensinar sinalizado na pesquisa pelas (não) respostas remete a âmbitos fundamentais da dimensão subjetiva do trabalho do professor, embora não se pode dissociá-la das condições objetivas de trabalho no contexto escolar.

As manifestações dos dezesseis sujeitos que responderam à questão "quais são as maiores dificuldades de conteúdos de conhecimento e metodologia que encontra na prática pedagógica?" mostram aspectos importantes sobre a formação teórico-metodológica do grupo. Elas foram organizadas em sete categorias, discutidas a seguir.

a) Todos os sujeitos manifestaram alguma necessidade, mas, na maioria das respostas não há identificação de conteúdos de conhecimento da área, ou seja, reforça-se a falta de definição sobre o objeto de ensino em LP, o que o torna um terreno movediço, sem suporte em que se ancorar ou direção para se movimentar, indo à contramão da "atividade", como definida por Leontiev. Um dos depoimentos, por exemplo, é muito significativo, quando define que a dificuldade são Alunos do $2^{\circ}$ ciclo que não possuem uma base consistente, o que demanda que se trabalhe com esta base, e isto compromete o ensino aprendizagem dos conteúdos. Sem negar a importância do que esse argumento expressa, ele, além de não definir o conteúdo ou aspecto metodológico do ensino solicitados na pergunta -, situa o problema fora do âmbito de atuação do sujeito. É representativo, também, de muitas situações da realidade escolar, em que alunos passam de um ano para outro sem obter as aprendizagens básicas, exatamente porque, no paradoxo, faltam-lhes as aprendizagens básicas. Como se essa "base" fosse uma abstração, não conteúdos que devessem ser aprendidos e, constatada a ausência, ensinados pelo professor.

b) As necessidades metodológicas são objetivadas na forma de material pedagógico (seis ocorrências) e de atividades pedagógicas (duas ocorrências), manifestações assim exemplificadas: Falta diversidade textual; Material, recursos adequados aos conteúdos; Novas fontes bibliográficas; Material para pesquisa, na escola, para repassar os conteúdos exigidos em cada ciclo ou turma (na maioria das vezes usamos o diário dos anos anteriores para amarrar nosso trabalho [...]; Os livros atuais não trazem gramática, nem textos bons para trabalhar; Poucos materiais disponíveis para apoiar-se no desenvolvimento do currículo no município; Sugestão de atividades; Ter sempre atividades inovadoras para as crianças que ainda não estão alfabetizadas.

Os depoimentos patenteiam a visão salvacionista conferida pelo grupo de sujeitos ao material pedagógico, que ocupa o espaço teórico e metodológico do ensino. O livro didático é tratado com naturalização, como integrante desse processo, e é cobrado por suas possíveis lacunas. Por essa visão, o próprio professor - e por si mesmo! - apresenta-se expropriado do saber e dependente de materiais e orientações externas. Os exemplos ainda evidenciam um anseio por renovação das práticas, porém também advindas de fontes externas, como sugestão. Aparentemente, pelos depoimentos, o saber que possuem sobre a área não permitiria a esses professores desenvolver suas próprias metodologias e organizar por si mesmos as atividades pedagógicas.

Observe-se que conteúdo e metodologia não podem ser vistos como categorias independentes e dissociadas, pois o próprio objeto de ensino contém indicativos para a metodologia de trabalho. Os próprios conteúdos são mediadores da relação do indivíduo com a realidade, o que significa que o ensino precisa ser organizado e realizado de forma a promover a apropriação dos conceitos científicos, que se tornarão instrumentos mediadores 
culturais a atuarem no próprio processo de ensino e aprendizagem.

c) A formação - continuada (cinco ocorrências) e inicial (duas ocorrências) também é manifesta nas respostas sobre as necessidades de conteúdos e metodologias, demonstrando, talvez, uma compreensão de que ela seja a origem ou explicação dos problemas. Assim, as respostas expressam: Falta de conhecimento do professor (eu); Estudar mais; Faltam cursos específicos; Falta formação continuada para a alfabetização; Encontros com professores alfabetizadores; Conteúdos pouco estudados durante a graduação; e Conteúdos superficialmente repassados.

A apresentação desses elementos é importante porque estão ligados ao objeto da pesquisa, embora sejam mencionados pelos sujeitos na inversão da possível relação causa e consequência: em vez de manifestarem as necessidades, mencionam por que as teriam.

d) Não saber trabalhar com alunos que têm dificuldades (três ocorrências) e não saber trabalhar com a diferença de nível de conhecimento entre os alunos (uma ocorrência). Esses depoimentos parecem evidenciar problemas do saber do professor na identificação de conhecimentos necessários ao aluno e na forma de organizar os conteúdos de ensino que devem ser priorizados em casos ou momentos específicos do processo. Em ambas as possibilidades, presencia-se o desejo de homogeneização dos estudantes e do aluno ideal, e aquele que fuja desse parâmetro torna-se um fator de risco para a aprendizagem, que deveria ser tomada no seu desafiador movimento de atuar em capacidades possíveis de se desenvolverem no aluno. Um movimento que exige a definição, pelo professor, dos saberes daquela criança e suas possibilidades de desempenho, para que possa planejar um ensino que atue na zona de desenvolvimento proximal (VIGOTSKI, 1998).

e) Apenas três elementos das manifestações relacionam-se a algum tipo de conteúdo a ensinar: "Elementos de ortografia (uma ocorrência) e gramática" (uma ocorrência), "Fases de leitura e escrita" (uma ocorrência). Gramática e ortografia são grandes partes do ensino da língua materna, que se dividem em conteúdos específicos, o que torna essas expressões muito abrangentes e generalizadas, mas é possível que o sujeito se refira a isso tudo, mesmo, porque se trata de uma quantidade de conhecimentos que é inviável de se obter num curso de pedagogia com a estrutura curricular do aqui referido. Por outro lado, as expressões remetem-se à dimensão normativa da LP. "Fases de leitura e escrita", isoladamente, como se apresenta na resposta, também se situaria entre as questões generalizantes e sem focos específicos, podendo se referir a todo o conhecimento necessário no desenvolvimento da alfabetização. Pode-se, também, considerando o contexto da pesquisa, no qual os professores recebem formação continuada orientada por mecanismos de políticas educacionais oficiais, interpretar tal expressão como relacionada às hipóteses de construção da escrita, pela criança, fundamentadas na teoria da psicogênese.

f) Duas manifestações referem-se ao desenvolvimento de atitudes: Gosto e interesse por ler, opondo-se à Leitura por obrigação. Acredita-se que tais apontamentos refiram-se à leitura fruição e a aspectos pragmáticos da leitura, mas é importante destacar, a partir de Britto (2009, p. 26), que "a formação do gosto se relaciona às experiências culturais e intelectuais, à inserção da pessoa num universo de relações complexas", e que "[...] a atividade da leitura (e da escrita) exige rigor e perseverança e, portanto, é muitas vezes penosa, [...] distinta de atividades lúdicas ou de processamento automático". Com essa argumentação o autor rechaça "a pedagogia do gostoso", que deve ser expurgada da escola, desde o início da escolarização, com a oferta, à criança, de "conteúdos que manifestem realidades e indagações intelectuais que estão além do seu referencial cotidiano" (BRITTO, 2009, p. 26). 
g) O planejamento é manifesto duas vezes como necessidade dos sujeitos: Preparar com mais atenção; Tempo para a devida preparação das aulas. Trata-se de fator importante do processo de organização do ensino, em todas suas dimensões. Está para além de conteúdos e metodologias e relaciona-se às condições de trabalho que são dispostas para o professor, como o tempo, exemplificado no depoimento. Envolve também conhecimento da dimensão teórica e curricular da disciplina, assim como das condições para efetivação do ensino.

A indefinição dos aspectos teóricos e metodológicos relativos a conteúdos e metodologias da disciplina discutidos nessa sessão denota importantes desafios e impasses no ensino de língua materna entre o grupo de egressos do curso de pedagogia sujeitos da pesquisa. Indefinição que pode ser resumida em um de seus depoimentos: os desafios $e$ dúvidas são frequentes.

\section{Reflexões finais: busca de uma síntese a partir dos desdobramentos do complexo processo formador}

Os resultados deixam evidentes que há, entre os sujeitos, algum conhecimento sobre fundamentos da linguagem e um movimento de compreensão da dimensão constitutiva da interação e da linguagem, como discutido nas primeira e segunda sessões deste artigo. Contudo, a análise, na sessão subsequente, mostra que os conhecimentos não são suficientes para a devida operacionalização teórico-metodológica da prática pedagógica. Ou seja, os resultados sinalizam que a formação não foi suficiente para que desenvolvessem uma sólida base epistemológica que lhes permitisse o discernimento necessário ao trabalho pedagógico com autonomia de conhecimento e que pudesse ser mobilizada nas diferentes situações de ensino de língua materna. Sinalizam limites à ancoragem da prática em bases científicas de conhecimento, que lhes permitam organizar o ensino e suas fontes de referência, de forma a mobilizar os saberes veiculados no curso de graduação e promover um ensino que contribua à aprendizagem das crianças da classe trabalhadora. Sinalizam, ainda, a ocorrência de um trabalho alienado, cujo objeto não tem sentido para os sujeitos, e uma abdicação do controle desse trabalho, uma vez que os egressos se mostram desorientados quanto ao que ensinar, expropriados de saberes e dependentes de condução externa para as definições de planejamento, conteúdos e metodologias, até por falta de clareza na diferenciação entre conteúdos, metodologias e atividades. Não se pode deixar de lado, no entanto, a interferência da forma como as mudanças conceituais sobre a linguagem, discutidas na primeira parte deste texto, foram introduzidas nas escolas de EF, muitas vezes reduzidas a orientações e alterações formais.

$\mathrm{Na}$ perspectiva dessa análise, que valoriza as condições materiais e simbólicas de vida e trabalho do professor, tanto os saberes que circulam no seu universo de trabalho, quanto as condições em que se constituiu sua formação são fatores determinantes. Assim, os resultados precisam considerar também, a existência e o nível de identificação desses sujeitos, enquanto foram acadêmicos, com o curso de pedagogia. A esse respeito, algumas condições são significativas na composição do grupo de egressos, como, por exemplo, o fato de $64 \%$ deles terem mais de dez anos de docência, e a maioria já atuar como docente, quando fez a graduação. É possível que, para essa maioria, a real motivação para cursar pedagogia tenha sido uma exigência legal ${ }^{10}$. E que esse grupo seja representativo do contexto educacional brasileiro do período.

Este estudo evidenciou alguns limites na formação dos egressos, que podem ser relacionados à formação inicial, mas também à continuidade da formação, pelo modo como os sujeitos se definem e se posicionam ante a experiência profissional e a sua relação 
com o conhecimento. As mediações da cultura que ocorrem na universidade e na escola os ambientes de formação e trabalho - e as interações com o contexto são constitutivas da formação do professor de língua materna, visto que as condições concretas da vida e a sua forma de inserção na prática e relações sociais são fatores essenciais ao seu desenvolvimento.

Assim, não se pode relativizar a força dos determinantes do contexto de trabalho na configuração da formação profissional desses egressos. Como as manifestações referem-se a professores em exercício no magistério, pode-se depreender que também dialogam com orientações educacionais emanadas dos órgãos oficiais, com suas características de homogeneização e verticalização, e seus mecanismos centralizados de difusão (ex. Próletramento, $\left.\operatorname{Profa}^{11}\right)$. Ou seja, os limites identificados na formação não podem ser atribuídos apenas ao curso de graduação. Para analisá-las, há que se pensar no sistema educacional em sua totalidade e nas relações entre sujeitos, conhecimento e educação.

A pesquisa evidencia a complexidade da formação desse professor que ensina língua materna nos anos iniciais do EF, assim como reforça o argumento de que essa formação não se esgota na universidade, pois, para se constituir, perpassa, também, por diversas mediações com o conhecimento, a cultura, a prática e com outros sujeitos.

Neste caso específico, que se refere a um grupo de professores com vários anos de experiência, os efeitos das duas principais condições formadoras já se materializam no trabalho educativo: formação inicial e experiência docente. Mesmo assim, as informações da pesquisa apontam que esses egressos caracterizam aspectos mais pragmáticos da língua para justificar seu ensino, inclusive quando demonstram suas concepções. Foram poucos os casos de reconhecimento do papel desse aprendizado para a constituição pessoal dos alunos e sua inserção crítica na realidade, pela possibilidade de acesso e relação com o conhecimento que disponibiliza e pelos conteúdos que veicula. Do mesmo modo, quando se referem aos desafios e impasses de sua atuação profissional, os elementos mais pragmáticos também se sobressaem. Parecem evidências de que a relação com o conhecimento, embora devesse ser constitutiva do ser professor, inclusive na dimensão política de sua abrangência, é elemento conflituoso da atuação pedagógica e da reflexão desses sujeitos sobre o ensino de língua materna.

Observe-se que os desafios não se referem somente aos conteúdos específicos de linguagem, mas também a toda dimensão científica e técnica do ensino - conhecimentos teórico-metodológicos, conhecimentos pedagógicos, curriculares, de organização e planejamento, entre outros. Mesmo não restringindo a formação desses professores ao curso de pedagogia, esse fato suscita alguns questionamentos: a) estaria o curso dando conta da formação inicial de professores? b) a ampla abrangência da formação em pedagogia expressa nos projetos político-pedagógicos do curso permitiria uma formação mais adequada ao desenvolvimento do ensino de língua materna nos anos iniciais do EF? c) qual seria essa formação mais adequada e seu currículo?

Parece possível argumentar, portanto, que as questões apontadas pela pesquisa remetem à discussão sobre as finalidades do curso de pedagogia, sobre a reafirmação do lócus formador do professor dos anos iniciais, a definição dos currículos apropriados para essa formação, enfim, à ampla e complexa questão sobre a identidade do curso e do pedagogo ${ }^{12}$. Talvez a dimensão de conflito identificada na pesquisa entre as necessidades de formação nos anos iniciais e as possibilidades dos professores que a efetuam aponte a necessidade de um redimensionamento na formação do professor, que também passe por redimensionar o curso de pedagogia. 


\section{Bibliografia}

ALMEIDA, Benedita de; FRANCISCHETT, Mafalda Nesi; PEDROSO, André P. Perfil e representações de egressos de curso de pedagogia no constituir-se professor. Seminário Nacional de Educação, 3 - Semana de Pedagogia, 14, Francisco Beltrão. Qual Educação? Qual Escola? Anais... Francisco Beltrão: UNIOESTE, 2010. p. 01-16. 01 CD-ROM.

BAKHTIN, Mikhail. Marxismo e filosofia da linguagem. 9. ed. São Paulo: Hucitec, Annablume, 2002.

BAKHTIN, Mikhail. Estética da criação verbal. São Paulo, Martins Fontes, 2000.

BERALDO, Tânia Maria Lima; OLIVEIRA, Ozerina Victor. Comunidades epistêmicas e desafios da representação nas políticas curriculares do curso de Pedagogia. Revista Teias, p. 1-19. v. 11, n. 22, maio/agosto 2010 (Online). Disponível in:

http://www.periodicos.proped.pro.br/index.php?journal=revistateias. Acesso em 13/09/2010.

BRASIL. Ministério da Educação. Conselho Nacional de Educação. Parecer CNE/CP 05/2005. Diretrizes Curriculares Nacionais para o Curso de Graduação em Pedagogia, licenciatura. Diário Oficial da União, Brasília, 15 de maio de 2006.

BRASIL. Ministério da Educação. Legislação. Lei n. 9.394, de 20 de dezembro de 1996. Estabelece as Diretrizes e Bases da Educação Nacional. Diário Oficial da União, Brasília, v.134, n.248, 23 dez 1996. Seção 1, p.27834-27841.

BRITTO, Luiz Percival L. Educação linguística escolar: para além das obviedades. In: CORREA, Djane A.; SALEH, Pascoalina B. O. (Orgs). Estudos da linguagem e currículo: diálogos (im)possíveis. Ponta Grossa: UEPG, 2009.

BRZEZINSKI, Iria. Pedagogia, pedagogos e formação de professores. Campinas (SP): Papirus, 1996.

COOK-GUMPERZ, Jenny. A construção social da alfabetização. Porto Alegre: Artes Médicas, 1991.

FARACO, Carlos Alberto; CASTRO, Gilberto de. Por uma teoria linguística que fundamente o ensino de língua materna (ou de como apenas um pouquinho de gramática nem sempre é bom). Educar em Revista, Curitiba, v. 15, p. 01-09, 1999. Disponível in:

http://www.educaremrevista.ufpr.br/arquivos_15/faraco_castro.pdf Acesso em 14/03/2008.

GERALDI, J. Wanderley. Portos de passagem. São Paulo: Martins Fontes, 1997.

KLEIMAN. A. Os significados do letramento: uma nova perspectiva sobre a prática social da escrita (Org.). Campinas, SP: Mercado de Letras, 1995.

LEONTIEV, Alexei N. Uma contribuição à teoria do desenvolvimento da psique infantil. In: VYGOTSKY, Lev Semenovich. LURIA, Alexander Romanovich. Linguagem, desenvolvimento e aprendizagem. Trad. de Maria da Penha Villalobos. São Paulo: Ícone, 1988. p.59-83.

LESSA, Sérgio. Sociabilidade e individuação: a categoria da reprodução na ontologia de Lukacs. Maceió: Edufal, 1995.

MARCELO, Carlos. A identidade docente: constantes e desafios. Form. Doc., Belo Horizonte, v. 01, p. 109-131, ago./dez. 2009. Disponível em 
http://formacaodocente.autenticaeditora.com.br. Acesso em 22/01/2010.

MARINHO, Marildes. A Língua Portuguesa nos currículos de final de século. In: BARRETO, Elba Siqueira de Sá. Os currículos do ensino fundamental para as escolas brasileiras. Campinas, SP: Autores Associados; São Paulo: Fundação Carlos Chagas, 2000, pp. 43-90.

PIMENTA, Selma G. (Org.). Pedagogia: ciência da educação? São Paulo: Cortez, 2001.

PIMENTA, Selma G. Formação de professores: saberes da docência e a identidade do professor. Revista da Faculdade de Educação, São Paulo, v. 22, n. 2. p. 72-89, jul./dez. 1996.

POSSENTI, Sírio. Por que (não) ensinar gramática na escola. Campinas, Mercado de Letras; Associação de Leitura do Brasil, 1996.

SOARES, M. Letramento: um tema em três gêneros. 2. ed. Belo Horizonte: Autêntica, 2006.

TRAVAGLIA, Luiz Carlos. Gramática e interação: uma proposta para o ensino de gramática no $1^{\circ}$ e $2^{\circ}$ graus. São Paulo: Cortez, 1996.

UNIOESTE. Conselho de Ensino, Pesquisa e Extensão. Resolução n. 374/2007. Aprova o Projeto Político-pedagógico do curso de Pedagogia, do Centro de Ciências Humanas Campus de Francisco Beltrão. Cascavel: UNIOESTE/CEPE, 2007.

UNIOESTE. Conselho de Ensino, Pesquisa e Extensão. Resolução $n^{\circ} 155 / 2003$. Aprova Projeto Político Pedagógico do Curso de Pedagogia, do Centro de Ciências Humanas Campus de Francisco Beltrão. Cascavel: UNIOESTE/CEPE, 2003.

UNIOESTE. Conselho de Ensino, Pesquisa e Extensão. Resolução $n^{\circ}$ 239/99. Aprova o Projeto Político Pedagógico do Curso de Pedagogia, Campus de Francisco Beltrão. Cascavel: UNIOESTE/CEPE, 1999.

SHULMAN, Lee S. The wisdom of practice: essays on teaching and learning to teach. San Francisco: Jossey-Bass, 2004.

VARELA, J. Categorias espaço-temporais e socialização escolar. In: COSTA, M. V. (Org.). Escola básica na virada do século: cultura, política e currículo. Porto Alegre: FACED/UFRGS, 1995, p. 37-56.

WEBER, Silke. Profissionalização docente e políticas públicas no Brasil. Educ. Soc., Campinas, vol. 24, n. 85, p. 1125-1154, dez., 2003.

VYGOTSKY, Lev S. A construção do pensamento e da linguagem. Trad. Paulo Bezerra. 2. ed. São Paulo: Martins Fontes, 2009.

VIGOTSKI, Lev S. A formação social da mente: o desenvolvimento dos processos psicológicos superiores. 6. ed. Trad. José Cipolla Neto. São Paulo: Martins Fontes, 1998. 
Notas:

${ }^{1}$ Representações, espaços, tempos e linguagens em experiências educativas.

${ }^{2}$ Perspectiva em que a linguagem é tomada do ponto de vista do movimento constitutivo e alteritário das interações sociais e da dimensão das relações de sentido que se estabelecem entre enunciados e sujeitos. Impregnada de valores e concepções, constitui um campo ideológico em que se projetam as identificações dos sujeitos, distanciando-se, portanto, de qualquer "subjetivismo abstrato" (BAKHTIN, 2002).

${ }^{3}$ Essa data e as dos outros PPPs referem-se ao ingresso no $1^{\circ}$ ano do curso.

${ }^{4}$ Leitura e escrita referem-se, aqui, a movimentos produtivos de compreensão e expressão dos sujeitos, ultrapassando a simples dimensão técnica.

${ }^{5}$ Cf. Vigotsky (2009, p. 465), "O sentido de uma palavra é a soma de todos os fatos psicológicos que ela desperta em nossa consciência. Assim, o sentido é sempre uma formação dinâmica, fluida, complexa, que tem várias zonas de estabilidade variada. O significado é apenas uma dessas zonas do sentido que a palavra adquire no contexto de algum discurso e, ademais, uma zona mais estável, uniforme e exata." Ou seja, o significado é convencionalmente estabelecido pelo social e é mais estável; o sentido refere-se à interpretação que cada sujeito histórico atribui ao signo, no contexto em que ele é usado.

${ }^{6}$ Ideologia considerada como o conjunto dos reflexos e interpretações da realidade social e natural, que tem lugar no cérebro do homem e se expressa por meio de palavras, no espaço de contradição inerente à realidade e ao signo/palavra/interação verbal (BAKHTIN, 2002).

${ }^{7} \mathrm{O}$ conjunto de conhecimentos, compreensões, habilidades e disposições necessárias à atuação efetiva do professor numa determinada situação de ensino (SHULMAN, 2004).

${ }^{8}$ Usa-se a expressão língua portuguesa (LP) na pesquisa com os sujeitos, por ser a denominação curricular da disciplina.

${ }^{9}$ Razão por que sua quantidade total é maior que a quantidade de sujeitos respondentes.

${ }^{10}$ Trata-se do estabelecido nas disposições transitórias da LDB-9394/96 (BRASIL, 1996) para que, no prazo de dez anos de sua promulgação, a formação para a docência ocorresse no ensino superior.

${ }^{11}$ Duas propostas de formação continuada de professores alfabetizadores propostas pelo MEC, realizado com secretarias de educação estaduais e municipais.

${ }^{12}$ Questão que é objeto de pesquisa dentro do grupo RETLEE e não constitui foco específico deste texto.

Recebido em: $\quad$ 13/11/10

Aprovado em: $\quad 20 / 03 / 11$ 